\title{
Book Information: Scared Sick: The Role of Childhood Trauma in Adult Disease by Robin Karr-Morse, with Meredith S. Wiley
}

\author{
Basic Books, 2012, 301 pages
}

\author{
Nicole S. Kluemper
}

Published online: 31 January 2014

(C) Springer International Publishing 2014

The author of this book does a wonderful job of explaining, in detail, how trauma experiences impact diseases of the body. She takes the reader on the same journey that she embarked upon in discovering this information, which gives the exploration a sense of continuity that it might otherwise lack. The writer begins with the now famous Adverse Child Experiences (ACE) study headed by Dr. Vince Felitti and the Centers for Disease Control and Prevention, and the many correlations between childhood traumatic experience and adult disease. From there, the author moves into a discussion of evidence in favor of the hypothesis that the youngest survivors of trauma are the hardest hit. Early trauma and its impact on the embryo or the child is explained in a way that will make the reader rethink everything he/she knows about such early life experiences.

As an example, Ms. Karr-Morse discusses research in which new born rat pups are exposed to repetitive pain in the form of daily needle pricks. This is meant to simulate the daily pain a premature infant might experience as a result of being born into the world before his/her skin is fully ready for the rough and often painful environment of the outside world. In the research, the rat pups grow up to display a greater preference for alcohol than their non-pain exposed peers. These rat pups were also more withdrawn and hypervigilant as adults, and displayed a lower pain threshold. If the author's hypothesis is correct, there are traumatic events taking place in hospitals all over the world on a daily basis that most of us are not even thinking of as trauma. Ms. Karr-Morse does not suggest that physicians stop this life saving treatment of young children, but rather she offers up this research as a means of understanding that early experiences do account for expressed characteristics later on in life.

N. S. Kluemper $(\bowtie)$

Institute on Violence, Abuse \& Trauma (IVAT), Alliant International University, 10065 Old Grove Rd, \#101, San Diego, CA 92131, USA

e-mail: nkluemper@alliant.edu
Epidemiology is then discussed, and how genes hold the potential to display any number of traits, but how environment determines much more of this process than ever thought possible. Research on diseases such as Schizophrenia, Diabetes, and Cancer are widely utilized throughout the book. It is suggested that medical doctors should take the time to inquire routinely as to trauma history during the intake process, as the effects of trauma cannot be overlooked when treating disease, even if the basis of that disease has traditionally been thought of as purely biological. The author then moves into a discussion of how trauma experiences are magnified when and if there is "nowhere to run," in the case that the parent or caregiver is the actual perpetrator of the trauma or child abuse. The book then moves into a discussion of how adult survivors and their therapists can take steps to minimize the impact of childhood trauma.

This book was interesting and, for the most part, easy to read. This book is written for members of the field of mental health with some background understanding of the parts of the brain and the various theories of attachment and trauma. This book does make a significant contribution to the field in that it brings together information from medicine and psychology and attempts to apply both in a manner that is consistent with cutting edge patient care. Ms. Karr-Morse encourages professionals within the field to consider not only the effects of early trauma, but the confounding effects of additional "little traumas" throughout the lifespan. The size of the book is in line with amount of subject matter presented, and the author does not belabor specific points such that the reader becomes bored. The most attractive feature of this book was the application to patient care toward the end. The author gives an overview of various treatment modalities which are now combining treatment of the mind with that of the body, and she provides practical but not overly simplified advice to readers who might be living with the lasting effects of their own childhood trauma. 